\title{
Science Anxiety and Gender in Students Taking General Education Science Courses
}

\author{
M. K. Udo, ${ }^{1}$ G. P. Ramsey, ${ }^{1}$ and J. V. Mallow ${ }^{1,2}$
}

Earlier studies [Mallow, J. V. (1994). Gender-related science anxiety: A first binational study. Journal of Science Education and Technology 3: 227-238; Udo, M. K., Ramsey, G. P., Reynolds-Alpert, S., and Mallow, J. V. (2001). Does physics teaching affect gender-based science anxiety? Journal of Science Education and Technology 10: 237-247] of science anxiety in various student cohorts suggested that nonscience majors were highly science anxious (SA), regardless of what science courses they were taking. In this study, we investigated science anxiety in a cohort consisting mostly of nonscience majors taking general education science courses. Regression analysis shows that the leading predictors of science anxiety are (i) nonscience anxiety and (ii) gender, as they were for different cohorts in the earlier studies. We confirm earlier findings that females are more SA than males. Chi-square analysis of acute science anxiety shows an amplification of these differences. We found statistically significant levels of science anxiety in humanities and social science students of both genders, and gender differences in science anxiety, despite the fact that the students were all enrolled in general education science courses specifically designed for nonscience majors. We found acute levels of anxiety in several groups, especially education, nursing, and business majors. We describe specific interventions to alleviate science anxiety.

KEY WORDS: science anxiety; nonscience majors; gender.

Students' choices of college courses and future careers are often dictated by how comfortable they feel about certain subjects. It is not uncommon for students to shy away from or perform poorly in science courses, due to what is now a well-known phenomenon, science anxiety (Mallow, 1986). Like its relative, math anxiety (Tobias, 1978), science anxiety in the most extreme cases paralyzes students who by any measure of intelligence and hard work, should do well. In practice, science anxiety acts as a career filter, preventing students from entering certain fields because they fear enrolling in the prerequisite science courses. Female students are especially affected, and their small numbers in some fields such as physics is an unfortunate consequence.

\footnotetext{
${ }^{1}$ Department of Physics, Loyola University Chicago, Chicago, Illinois 60626

${ }^{2}$ To whom correspondence should be addressed; e-mail: jmallow@ luc.edu.
}

The causes of science anxiety are many, including past bad experiences in science classes, exposure to science anxious (SA) teachers who are teaching science in elementary and secondary schools, lack of role models, gender and racial stereotyping, and the stereotyping of scientists in the popular media. Though some degree of anxiety may be helpful in the learning process, a high level of anxiety impedes optimum performance on science learning (Mallow and Greenburg, 1982).

Chiarelott and Czerniak $(1985,1987)$ studied schoolchildren in fourth through ninth grade (ages 9-14) and demonstrated that science anxiety and its gender differences begin as early as age nine. The females and physics project (Beyer and Vedelsby, 1983; Beyer et al., 1985, 1988; Beyer and Reich, 1987; Beyer, 1991, 1992) studied classroom interactions in the Danish high school, and implicated science anxiety as a factor creating special obstacles for female students in both the humanities and the science tracks. 
Related to the early manifestation of science anxiety and its gender bifurcation is the question of who is teaching science. A survey of US high school physics teachers (Neuschatz and Alpert, 1996) yielded the startling statistic that barely half of the people currently teaching physics in high school had studied 3 years (six semester-courses) or more of university physics. Fewer than a third had a bachelor's degree in either physics or physics education, resulting in inadequate preparation of the teacher in the subject matter. Poor preparation, possibly coupled with feelings of inadequacy manifesting themselves in some form of anxiety, may then be transmitted to the students, thus perpetuating the science anxiety cycle. Another possible source of anxiety related to learning science (and mathematics) is rooted in the student's level of intellectual development. Students in high school and even university are usually in the process of passing from the concrete reasoning stage to the formal reasoning stage (Piaget, 1967). High school physics is generally taught at the concrete level and university physics at the formal level. This presents a dilemma, since about half of the students taking university science are still concrete thinkers, whereas almost half of the high school seniors taking science are making the transition to formal thinking (Renner et al., 1976; Barnes, 1977; Barnes and Barnes, 1978; Cohen et al., 1978). Thus, the needs of about half of each group are not met either in high school or in university. This mismatch between the student's intellectual development and the teaching method can be one more factor contributing to science anxiety.

Finally, science anxiety and science enrollments are surely affected by role models, or the lack thereof, with physics being the worst in this regard. In addition to the stereotyping of scientists (Vedelsby, 1991; Mallow, 1993; Brownlow et al., 2002), the low numbers of female (and minority) physics teachers also suppress the number of students who might see themselves as future physicists. In studies done several years ago, it was found that fewer than $25 \%$ of high school physics teachers were women (Neuschatz and Alpert, 1996). Among physics professionals, women constituted $9 \%$ of the workforce (NSF, 1996). The percentage of female faculty in $\mathrm{PhD}$-granting physics departments in 1996 was $6 \%$ and the percentage of newly hired female physics faculty in such departments was 9\% (Curtin et al., 1997). Although these numbers have increased markedly in the last decade, only about $10 \%$ of physics faculty today are female (Ivie, 2004). There is still such a gender discrepancy as to discourage young women from considering physics as a career. Although some enrollment gender bifurcations, e.g., in biology and mathematics, appear to have decreased markedly over the last few years, others seem to persist. The "chilly climate" for females in science classes at various levels has been well-documented for several decades in US (e.g., Brush, 1991 and references therein; AAUW, 1992; Whitten et al., 2003) and in Denmark (Vedelsby, 1991; Mallow, 1993; Beyer et al., 1988; Tobias et al., 2002).

Since the late 1970s, theoretical and practical advances have been made in correlating students' feelings with their ability to understand the subject matter, as well as with their career choices (Tobias, 1978; Mallow, 1994, 1998, and references therein). Some of these studies have specifically focused on the connection of gender to the interaction of feelings and cognition. In particular, the role played by science anxiety in maintaining gender differences in science learning at all levels has been examined. Although it is very difficult to adduce causation from correlation, it seems that enrollment patterns and science anxiety are negatively synergistic. Science anxiety can lead to science avoidance which in turn plays a role in producing unequal proportions of males and females as students and teachers in both science and nonscience fields. Brownlow et al. (2000) have shown that females who were science anxious interpreted their ability to do science more negatively than males, and took fewer science courses. The stereotyping of various nonscience fields as "female" seems to have a chilling effect on male enrollments (Mallow, 1997). These gender bifurcated proportions in turn communicate implicit messages about the gender appropriateness of these fields. Females especially tend to interpret their relative absence in certain areas of science as a sign of their inability to succeed in those areas (Kelly, 1981; Johnson and Murphy, 1984; Beyer and Reich, 1987; Beyer et al., 1988; Jones and Wheatley, 1988, 1990; AAUW, 1993; Mallow, 1993). These attitudes thus work as negative feedback, reinforcing science anxiety, and the cycle perpetuates itself. Intervention techniques dealing with both mathematics and science anxiety have been developed (Alvaro, 1978; Tobias, 1978, 1985; Beyer and Vedelsby, 1983; Mallow, 1986; Beyer, 1991, 1992; Schneider and Nevid, 1993) and are discussed in Appendix A.

The role of science anxiety, its international character, and its gender dependence in science learning was demonstrated by Mallow (1994). Using 
the Science Anxiety Questionnaire developed by Alvaro (1978), Mallow performed the first binational study of science anxiety by measuring science anxiety in a group of American and Danish students age 17 and up. His main objective was to see if science anxiety was related to gender or cultural differences. The cohort consisted of an almost equal distribution of science and nonscience majors, with slightly more females $(55 \%)$ than males $(45 \%)$. For both nationalities he found that the strongest predictor of science anxiety was nonscience anxiety; i.e., anxiety on the nonscience items of the questionnaire. Keeping nonscience anxiety constant, the next strongest predictor was gender. Both American and Danish females expressed more science anxiety than their male counterparts. Also, in general the Danish students reported lower levels of science anxiety than the Americans. Udo et al. (2001) measured science anxiety in students enrolled in physics courses at Loyola University Chicago. The cohort consisted mostly of science majors, $57 \%$ of whom were female. The main objectives of the study were to ascertain whether the factors contributing to science anxiety had remained constant over time since Mallow's 1994 work, and whether the exposure to one semester of physics affected anxiety level. It was confirmed that nonscience anxiety remained the major contributor to science anxiety, followed by gender. The evaluation of anxiety at the beginning and end of the various physics courses showed modest decreases in both science and nonscience anxiety. Isolated cases of substantial reduction in science anxiety were observed in two interactive pedagogy sections (Hake, 1998), where the gender of the teacher matched that of the students whose anxiety was lowered. These modest improvements so late in the student's education are consonant with the previous findings (Chiarelott and Czerniak, 1985, 1987) that the emotional baggage of science anxiety is acquired at a very early age, long before students encounter college physics.

There was a crucial difference between the cohorts of Mallow (1994) and Udo et al. (2001). The former study's cohort was drawn from students taking a wide variety of courses both in science and nonscience. The latter study's cohort was drawn entirely from science courses, and mostly those designed specifically for science students: algebra-based physics for biology and premedical students, and calculus-based physics for chemistry and physics majors. Thus, in contrast to Mallow's results, Udo et al. not surprisingly found that in general the major field of study was not a significant predictor of science anx- iety. One is then led to ask, is science anxiety less prevalent in science courses specifically designed for nonscience students?

\section{THE PRESENT STUDY}

\section{Purpose}

Based on the results obtained from these two different cohorts (Mallow, 1994; Udo et al., 2001), we decided to investigate the levels of anxiety of a population of nonscience majors taking general education science courses designed specifically for them. The development of such courses over the last few decades is based on the premise that nonscience majors will learn science better if they are in a class environment without the stress of competition with science majors, and with a curriculum designed for their mathematical level and their interests. If such courses were in fact meeting their stated objectives, there should be little science anxiety, both for females and males. The present study investigates the validity of this hypothesis. The main objectives of this investigation are as follows.

(1) To ascertain whether the factors contributing to science anxiety as determined in previous investigations: nonscience anxiety, gender, and nonscience major, are the same for this hitherto unexamined group.

(2) To investigate science anxiety in females and males in specific nonscience fields of study.

(3) To compare the levels of acute anxiety expressed on science and nonscience items for the different populations: one with a mix of science and nonscience majors (Mallow, 1994), one comprising mostly science majors (Udo et al., 2001), and the current study, comprising mostly nonscience majors, each in science courses designed specifically for the respective group.

\section{Research Design and Methodology}

\section{Instrument}

The Science Anxiety Questionnaire used in this study and the earlier ones (Mallow, 1994; Udo et al., 2001) was developed by Alvaro (1978) as part of her investigation of the effectiveness of the Science Anxiety Clinic at Loyola University Chicago. The 
questionnaire consists of 22 science and 22 nonscience scenarios, with emphasis on analogous situations; e.g., studying for a physics exam vs. studying for a history exam. A copy appears in Appendix B. Students are asked to imagine themselves in the situations described in the questionnaire and to rate their level of anxiety on a five-degree Likert scale: "not at all," "a little," "a fair amount," "much," and "very much."

Based on a survey of 538 Loyola undergraduates enrolled in a variety of science courses, Alvaro developed factor scales to measure various forms of anxiety. She, and subsequently Hermes (1985), demonstrated that for several of these factors, significant decreases in anxiety (measured by this instrument, by electromyography (EMG), and by related self-report anxiety instruments) occurred for students in Science Anxiety Clinic groups over those in control groups. We have used the questionnaire since 1978 to select, from the pool of applicants to the Science Anxiety Clinic, those who actually manifest the anxiety. It has also been used by other researchers (see e.g., Brownlow et al., 2000). The reliability of the summated scales based on the 22 science items and the 22 nonscience items was reported by Mallow (1994) in his binational study. The items on both scales met the criteria of additivity, with coefficients 0.904 and 0.850 , respectively. Although some of the situations described in the questionnaire may seem unlikely to elicit anxiety, in fact every one of the science questions evoked anxiety in students (Mallow, 1994). Thus, their inclusion in the questionnaire together with their nonscience counterparts have indeed provided valid measures of science anxiety, as confirmed by correlation with results of other instruments, both self-reporting and physiological (Alvaro, 1978; Hermes, 1985).

\section{Cohort}

Loyola University Chicago is a private urban Jesuit institution, emphasizing a strong liberal arts education, with a substantial requirement of "core" or general education courses common to every major. Science courses are a component of this requirement. Loyola's student population is ethnically heterogeneous and spans socioeconomic classes and religions. Currently $>60 \%$ of its undergraduate student body is female. The cohort in the present investigation mirrors this diversity.

The age range in our cohort runs from 18 to the 30s. Eighty-four percent of the students were
18-24 years old, $7 \%$ were $25-29$ years old, and $4 \%$ were older than 30 , with the oldest being 61 . The gender distribution within each age range replicates our cohort distribution; namely, about 2/3 female.

The Science Anxiety Questionnaire was administered in class, unannounced, approximately 8 weeks into the semester, thus avoiding responses from students who had dropped the course early on. The cohort consisted of 500 students: 169 males and 331 females. They were selected from a variety of science core courses offered by three departments: Chemistry, Natural Sciences, and Physics, and most of them were nonscience majors, although a few science majors also enroll in these general education science courses. The participants were not preselected according to expressed science anxiety or any other criterion except the willingness of their instructors to relinquish about half an hour of classroom time for administration of the questionnaire.

The students were enrolled in one of the following courses for nonscience majors: Liberal Arts Physics, Astronomy (Physics Department), Life and Inquiry, Evolution and Genetics, Human Heredity, Human Reproduction, and Earth Science: the Changing Planet, Weather and Climatology, Concepts in Disease Causation, Human Impact on the Environment, and The Human Environment (Natural Science Department). In addition, we administered the questionnaire in Elementary Physiological Chemistry, a course for nursing students (Chemistry Department). The largest groups by field were: Humanities with $28.0 \%$ and Social Sciences with $27.0 \%$, followed by Business with $12.6 \%$. Other declared major groups accounted for $<10 \%$ each, whereas the undeclared majors comprised $11.4 \%$ of the cohort.

\section{RESULTS AND DISCUSSION}

\section{Multiple Regression Analysis}

In Table I, we present the cohort according to gender and major field of study, with related majors grouped under the same category. We performed a standard multiple regression analysis of the responses to the questionnaire, following the same procedure as in the previous studies. Table II shows the results presented in the same order as described in our earlier study (Udo et al., 2001). Nonscience anxiety accounts for the greatest proportion of the variance in science anxiety. Gender is the next most 
Table I. Cohort by Category and Gender

\begin{tabular}{lrc}
\hline Category of major & Male & Female \\
\hline Business & 31 & 32 \\
Education & 2 & 15 \\
Humanities & 52 & 88 \\
Mathematics & 20 & 9 \\
Nursing & 1 & 39 \\
Science & 2 & 17 \\
Social science & 41 & 94 \\
Undeclared & 20 & 37 \\
Total & 169 & 331 \\
\hline
\end{tabular}

important factor. For the present cohort, the choice of major field of study is a third significant predictor of science anxiety, but only for those students majoring in social sciences and humanities. The $\beta$-values in Table II are in agreement with the results of Mallow (1994) and Udo et al. (2001). For purposes of comparison, the $\beta$-values of nonscience anxiety, gender, and major field of study for our current and previous investigations are presented in Table III. In the present study, gender accounts for a larger proportion of the variance in science anxiety and has a higher statistical significance than in the previous works. Note also that fully two-thirds of the present cohort is female, compared with $57 \%$ in Udo's study and $55 \%$ in Mallow's cohort. This increase in the number of females probably explains the stronger indication of gender as a predictor for science anxiety in the present study. As the final column of Table III shows, the major field of study continues to be tertiary, but is now a significant predictor of science anxiety. As shown in Table II, social sciences and humanities majors are separately significant; the large number of these ma-

Table II. Regression Analysis Results ${ }^{a}$

\begin{tabular}{lccc}
\hline \multicolumn{1}{c}{ Variable } & $B$ & SE $B$ & \multicolumn{1}{c}{$\beta$} \\
\hline Gender & 0.247 & 0.042 & $0.186^{* * *}$ \\
Business major & 0.036 & 0.076 & 0.019 \\
Social Science major & 0.161 & 0.066 & $0.116^{*}$ \\
Humanities major & 0.186 & 0.066 & $0.131^{* *}$ \\
Science major & -0.096 & 0.110 & -0.030 \\
Education major & -0.144 & 0.112 & -0.043 \\
Mathematics major & -0.078 & 0.095 & -0.030 \\
Nursing major & -0.034 & 0.087 & -0.015 \\
Nonscience anxiety & 0.961 & 0.041 & $0.716^{* * *}$ \\
Constant & 0.082 & 0.098 & \\
\hline
\end{tabular}

Note. "Undeclared" majors are the excluded category. $B$, regression coefficient; SE $B$, standard error in $B ; \beta$, standardized regression coefficient.

${ }^{a}$ Multiple $R=0.768, R^{2}=0.590$, adjusted $R^{2}=0.582$.

${ }^{*} p<0.05 ;{ }^{* *} p \leq 0.005 ;{ }^{* * *} p<0.001$. jors is thus the dominant component of this Table III result. In Mallow's cohort (1994), comprising almost equal numbers of science and nonscience majors, the major field of study: broadly science or nonscience, contributed about as much as gender to the variance in science anxiety. In the cohort of Udo et al. (2001), consisting mostly of science majors, major field of study was not a consistent factor in predicting science anxiety, appearing only in the pretest results, with science and social science majors emerging as predictors; the $\beta$-value for science majors was negative, confirming that they are not SA. In summary, our present study's regression analysis confirms previous results: nonscience anxiety and gender are the strongest predictors of science anxiety, followed by major field of study. For the current cohort, this last predictor has been broken down by specific field. The social sciences and humanities majors in particular were significant predictors of science anxiety.

\section{Acute Anxiety}

Acute anxiety as described by responses "much" and "very much" was then examined by tabulating the questionnaire responses for each student. Students who responded "much" or "very much" to one or more items, whether science or nonscience, were classified as generally anxious (GA), whereas those who gave no responses "much" and "very much" were classified as not generally anxious (NGA). The total size of the cohort is $N=\mathrm{GA}+\mathrm{NGA}$. The GA group was further divided into SA, those who gave "much" or "very much" responses to one or more of the science items only, and the nonscience anxious (NSA), those whose anxiety was only due to nonscience items. That is, GA = NSA + SA. Table IV summarizes these tabulations for females and males of the cohort. For comparison, we include data from previous studies. We calculated the percentage of the cohort that is GA and the percentage of the GA population that is SA. We also carried out a chisquare analysis to determine if the proportion of SA females was significantly different from the proportion of SA males. We find that $15 \%$ more females than males are GA $(p \sim 0.001)$ and of the GA subset we find that $10 \%$ more females than males are SA ( $p \sim 0.001)$. Taking the customary standard for significance as $p<0.05$, these percentages are statistically significant, in agreement with the results of our previous study (Udo et al., 2001) of mostly science majors. The males in the present study exhibit the 
Table III. Comparison of $\beta$-Values for Each Study

\begin{tabular}{|c|c|c|c|c|c|c|}
\hline & \multirow[b]{2}{*}{ Mallow (1994) } & \multicolumn{2}{|c|}{$\begin{array}{l}\text { Udo et al. (2001) } \\
\text { entire cohort }\end{array}$} & \multicolumn{2}{|c|}{$\begin{array}{c}\text { Udo et al. (2001) } \\
\text { College Physics cohort }\end{array}$} & \multirow[b]{2}{*}{ Present work } \\
\hline & & Pretest & Post-test & Pretest & Post-test & \\
\hline Nonscience anxiety & 0.704 & 0.709 & 0.666 & 0.733 & 0.654 & 0.716 \\
\hline Gender & 0.146 & 0.097 & $0.083^{\mathrm{NS}}$ & 0.109 & 0.141 & 0.186 \\
\hline Major field of study & -0.155 & $-0.111^{a} ; 0.106^{b}$ & - & 0.135 & - & $0.116^{b} ; 0.131^{c}$ \\
\hline
\end{tabular}

Note. Only those majors with statistical significance are reported under the major field of study. NS, not significant $(p>0.05)$. The quantities not marked with NS are all significant at least to the level $p<0.05$.

${ }^{a}$ Science.

${ }^{b}$ Social science.

${ }^{c}$ Humanities.

same percentage GA/N as the American cohort investigated by Mallow (1994), but their SA/GA percentage is higher than all the males in previous studies. The females show a higher percentage for both GA/N and SA/GA than females in previous studies. We performed a pairwise chi-square analysis to determine if these apparent differences were significant. The pretest cohort of Udo et al. (2001) and the American cohort of Mallow (1994) were used for this comparison. No statistically significant differences were observed between the male cohorts. For females, we found significant differences $(p<0.001)$ when comparing their GA populations; statistical differences were observed for SA populations betweens the Udo et al. cohort and the present cohort, with the current one manifesting the higher anxiety levels.

This acute anxiety analysis shows that our cohort is highly anxious, with females exhibiting higher levels of anxiety than males on science items. Of those expressing general anxiety, most exhibit acute science anxiety: $95 \%$ of females and $85 \%$ of males. This high level of acute science anxiety observed across all major fields of study corroborates the results of the regression analysis that major field of study is a predictor of science anxiety. Could we attribute this high science anxiety level to the humanities and social science majors, since they make up about $2 / 3$ of the cohort? To answer this question, we tabulated the percentages of GA/N and SA/GA for each major in Table V. (Since the number of male respondents in some majors is very small, it is not possible to obtain statistically significant information regarding gender differences within those majors.) We note that females in general exhibit high levels of $\mathrm{GA} / \mathrm{N}$, ranging from $76 \%$ for science majors to $93 \%$ for education majors. For the majors with significant numbers of males and females (business, humanities, mathematics, and social science) the deviations of $\mathrm{GA} / \mathrm{N}$ and $\mathrm{SA} / \mathrm{GA}$ from the averages listed in Table IV are small; thus, no one major is skewing the average. No statistically significant differences in SA were observed for females in different majors: anxiety levels were uniformly high. Males in humanities and social sciences have significantly more SA than

Table IV. GA and SA Distribution

\begin{tabular}{|c|c|c|c|c|c|c|c|c|c|}
\hline & & & Total cohort $\mathrm{N}$ & NGA & GA & GA/N (\%) & NSA & SA & SA/GA (\%) \\
\hline \multirow[t]{3}{*}{ Present study } & Entire cohort & Female & 331 & 61 & 270 & 82.0 & 13 & 257 & 95.0 \\
\hline & & Male & 169 & 55 & 114 & 67.0 & 17 & 97 & 85.0 \\
\hline & & $p$ & & & & 0.001 & & & 0.001 \\
\hline \multirow[t]{6}{*}{ Udo et al. (2001) } & Pretest & Female & 194 & 65 & 129 & 66.5 & 29 & 100 & 77.5 \\
\hline & & Male & 146 & 61 & 85 & 58.2 & 21 & 64 & 75.3 \\
\hline & & $p$ & & & & 0.1 & & & 0.75 \\
\hline & Post-test & Female & 157 & 59 & 98 & 62.4 & 9 & 89 & 90.8 \\
\hline & & Male & 116 & 53 & 63 & 54.3 & 17 & 46 & 73.0 \\
\hline & & $p$ & & & & 0.1 & & & 0.005 \\
\hline \multirow[t]{6}{*}{ Mallow (1994) } & Danish cohort & Female & 63 & 28 & 35 & 56 & 10 & 25 & 71.0 \\
\hline & & Male & 36 & 17 & 19 & 53 & 13 & 6 & 32.0 \\
\hline & & $p$ & & & & 0.90 & & & 0.005 \\
\hline & American cohort & Female & 115 & 43 & 72 & 63 & 7 & 65 & 90.0 \\
\hline & & Male & 111 & 37 & 74 & 67 & 17 & 57 & 77.0 \\
\hline & & $p$ & & & & 0.5 & & & 0.025 \\
\hline
\end{tabular}


Table V. GA and SA Distribution for Each Major

\begin{tabular}{llcrrrrrr}
\hline & & Total cohort N & NGA & GA & GA/N $(\%)$ & NSA & SA & SA/GA $(\%)$ \\
\hline Business major & Female & 32 & 4 & 28 & 88 & 0 & 28 & 100 \\
& Male & 31 & 8 & 23 & 74 & 0 & 23 & 100 \\
Education major & Female & 15 & 1 & 14 & 93 & 3 & 11 & 79 \\
& Male & 2 & 0 & 2 & 100 & 2 & 0 & 0 \\
Humanities major & Female & 88 & 20 & 68 & 77 & 2 & 66 & 97 \\
& Male & 52 & 15 & 37 & 71 & 5 & 32 & 86 \\
Mathematics major & Female & 9 & 2 & 7 & 78 & 1 & 6 & 86 \\
& Male & 20 & 8 & 12 & 60 & 5 & 7 & 58 \\
Nursing major & Female & 39 & 5 & 34 & 87 & 2 & 32 & 94 \\
Science major & Male & 1 & 0 & 1 & 100 & 1 & 0 & 0 \\
Social science major & Female & 17 & 4 & 13 & 76 & 1 & 12 & 95 \\
\multirow{2}{*}{ Undeclared major } & Male & 2 & 0 & 2 & 100 & 1 & 1 & 50 \\
& Female & 94 & 21 & 73 & 78 & 3 & 70 & 96 \\
& Male & 41 & 17 & 24 & 59 & 2 & 22 & 92 \\
\hline
\end{tabular}

mathematics and science majors. This result substantiates Mallow's earlier claim (1994) for his American cohort, that male nonscience students were more SA than their science counterparts.

\section{SUMMARY AND CONCLUSIONS}

We investigated science anxiety of a cohort consisting mostly of nonscience majors taking a variety of science courses. The instrument used was the Science Anxiety Questionnaire. Multiple regression analysis confirmed previous results that the best predictor of science anxiety is nonscience anxiety, followed by gender. In this study, we found that a choice of major in humanities or social science now emerges as the third significant predictor, confirming with specifics the general result found by Mallow (1994) that a nonscience major is a predictor of science anxiety. However, his cohort included nonscience majors enrolled in a full range of introductory science courses. In the current study, by contrast, we found statistically significant levels of science anxiety in humanities and social science students of both genders, and gender differences in science anxiety despite the fact that the students were all enrolled in general education science courses specifically designed for nonscience majors.

Our analysis of acute science anxiety showed that the overall level of science anxiety is higher in the present cohort than in cohorts of earlier studies. Our results confirm previous observations that mathematics and science majors exhibit the lowest levels of anxiety, both for science and nonscience items, but females even in these majors are more anxious than males. We found acute levels of anxiety in several other groups; in particular, education, nursing, and business majors. This study corroborates previous results that females overall are more SA than males.

In addition, the high levels of science anxiety seen in the entire cohort can be attributed to the large numbers and high levels of acute science anxiety of humanities and social science majors. Our most important conclusion is therefore to (unfortunately) invalidate the hypothesis that science courses designed specifically for nonscience majors provide a lower anxiety learning environment, or lessen the gender differences in science anxiety. One likely cause is that the anxiety and its gender bifurcation long predate the college years (Chiarelott and Czerniak, 1985, 1987). There may of course be other causes, such as a mismatch of teaching approach by a professional scientist and learning style of nonscience students. Whatever the causes, we have shown here that classroom teaching alone is not enough, even with targeted courses. Fortunately, effective interventions for diminishing science anxiety (and its related but distinct malady, math anxiety) in both females and males, have been developed, both in and out of the classroom. We describe these in Appendix A.

It is possible that males, based on cultural expectations, are under-reporting their level of scienceanxiety. This would certainly be a typical response to the stereotypic pressures on males to specialize in science and to deny the need for emotional support. Similarly, females may be over-reporting their anxieties. This is an unavoidable shortcoming of 
self-report instruments. However, the anxiety measures of students in the Loyola Science Anxiety Clinic (Alvaro 1978; Hermes, 1985) included not only self-reports, but also electromyography (EMG), a physiological measure of tension. The scienceanxiety questionnaire results were consistent with the EMG measurements, both in preclinic and postclinic tests, thus providing an important measure of confidence in the validity of the self-reports of science anxiety.

One might also wonder about the possible relationship of age of students with science anxiety. Are the older students more anxious because they fear their preparation may be out of date, their study skills rusty? Is the age distribution similar for males and females or are the older students more likely to be female? As noted earlier, the age range in our cohort runs from 18 to the $30 \mathrm{~s}$ : $84 \%$ of the students were 18 24 years old, and the gender distribution within each age range mirrored the cohort distribution: about $2 / 3$ female. Given these statistics, we did not include age in the present study. A multi-year assessment of Loyola students taking algebra-trigonometry-based introductory physics for nonmajors found that, while older students' mathematics skills at the beginning of the course may be a bit rusty, they quickly overcome those hurdles and perform at least as well as the other students. We are considering a future study of the possible relationship of age with science anxiety.

One important finding of this investigation is that among the various major fields of study which emerged in our cohort, the education majors (mostly females), while exhibiting the highest levels of general anxiety, do not exhibit the highest levels of science anxiety. Nevertheless, this is not reassuring, because as Table $\mathrm{V}$ shows that level is still very high, and not statistically different from other groups. These are our future teachers, the very people who will be introducing young students to science. Given that female students are more SA than males, their career choices, driven by avoidance of science, still preclude them from assuming their rightful place in a technological society. Unfortunately, this situation seems to be perpetuated by the anxiety demonstrated by those who will be teaching the next generation. We plan to continue our investigation of science anxiety with a larger cohort consisting mostly of education majors, to address issues such as: choice of field of study, previous math preparation and/or prolonged absence from mathematics, age of student, and science background. We also hope to assess science anxiety in in-service K-12 teachers.

\section{APPENDIX A: WHAT CAN BE DONE?}

Techniques have been developed over the past several decades to help students (and teachers) alleviate their science and math anxiety, and to assist teachers in building student confidence in these subjects.

\section{Science Anxiety: Interventions for Students}

The Science Anxiety Clinic developed and conducted at Loyola University Chicago (Alvaro, 1978; Mallow, 1986), provides a model for science anxiety reduction. In the Clinic there were two facilitators: a science teacher and a psychological counselor, working with a group of six to ten students, for about 2 hours a week, over an 8 week period. (However, these techniques could be used by a single facilitator and/or a single student, over variable time frames.) The clinic reduces science anxiety by a three-pronged approach: science skills learning, changing of students' negative self-thoughts, and desensitization (through muscle relaxation exercises) to science anxiety producing scenarios. In each session all three approaches are blended.

Science skills learning includes: how to read science as distinct from history or literature (Mallow, 1991); techniques for organizing and solving word problems; ways to take notes in science classes, how to perform effectively in science laboratories, and how to take science tests and examinations. Females in particular come to recognize that their learning depends on asking questions in and out of class, and that they must have "hands-on" laboratory experiences.

Cognitive restructuring is a psychological technique for anxiety reduction (Ellis, 1962) based on the insight that such things as physics problems or chemistry laboratories are not intrinsically anxietyproducing. Rather, they are the stimuli for negative self statements which students tell themselves (usually unconsciously), such as, "No matter how hard I study, I'll never understand science;" "Science is not for girls;" "Everyone understands it but me." These self statements are the real stimuli provoking the anxiety responses. Cognitive restructuring is a technique for getting students to recognize their negative self statements, focus on the irrational beliefs which lie behind them, and then replace them with objective, emotionally neutral "coping statements." 
Systematic desensitization is a behavioral modification technique which trains students to relax their bodies in anxiety-producing situations. It consists of two components: progressive relaxation and desensitization to a self-generated anxiety hierarchy. Progressive relaxation (Jacobson, 1938) involves training students to relax each of a large variety of muscle groups upon command, given by either a facilitator or an audio tape. Students learn these techniques and practice them at home. At the same time, they develop a "science anxiety hierarchy": a list of about 10-12 science-related events, ordered from low to high anxiety. A typical low-anxiety event would be "You look through your science textbook." A medium anxiety event might be "You read a chapter and can't relate it to the class lectures." And a high anxiety event could be "You look at the exam and can't think of how to do any of the problems." At each session, the facilitator has the students relax their muscle groups, then presents two or three of these items, starting from the lowest, and monitoring whether the relaxation is maintained. Only when it is, does the facilitator go on to the next higher item. A 12 item hierarchy can be completed in about 4-6 weeks.

Studies were carried out on students at the Loyola University Science Anxiety Clinic (Alvaro, 1978; Hermes, 1985) to assess its effectiveness. A variety of instruments were used, including four questionnaires: a Math Anxiety Rating Scale (Richardon and Suinn, 1972), a science anxiety measure developed at Loyola (Alvaro, 1978), a general anxiety measure (Spielberger et al., 1970), and a general academic test anxiety measure (Alpert and Haber, 1960). In addition, the students' muscle tension was measured by EMG, while they imagined science anxiety hierarchy items. These studies demonstrated that the techniques used were effective in lowering students' science anxiety, irrespective of the students' majors.

Beyer and co-workers in Denmark have developed classroom methods for building science confidence, especially, but not exclusively among female students at the gymnasium level. These include group project work and thematic organization of the curriculum, as well as general restructuring of classroom interactions (Beyer and Vedelsby, 1983; Beyer et al., 1985, 1988; Beyer, 1991, 1992). With an imminent change in the Danish upper secondary educational system, mandating physics in first year for both science and nonscience students, the Ministry of Education is studying effective means of science anxiety reduction, especially for female students (Claussen, 2004).

\section{Math Anxiety: Interventions for Students}

Since the pioneering work of Tobias (1978, 1985), a good deal of work has been done on the interaction of affect and cognition in mathematics learning . In particular, the role played by gender has been studied (Segal, 1987; Harrington et al., 1992; Hall et al., 1999; Ho et al., 2000). Studies of middle school students indicated that gender is a predictor of math anxiety. This anxiety manifests itself in early mathematics training, as more elementary level teachers (mostly female) have math anxiety than other level teachers. Further, there is a significant negative correlation for affective (emotional) anxiety and performance in math courses (Ho et al., 2000). In addition, parents' attitudes about math are a factor in math anxiety and test performance (Hall et al., 1999). The net result is both math avoidance and poor performance in math courses.

Math anxiety intervention techniques are similar to those of science anxiety. Specific types of intervention include stress-inoculation treatment, a cognitivebehavioral approach (improving skills and overcoming anxiety) and desensitization, a behavior-only (relaxation) technique approach (Genshaft, 1982; Schneider and Nevid, 1993).

In spite of the similarities between math and science anxiety, the question of the role of math anxiety in science learning is still unresolved (Yater, 1986 and replies therein). Studies indicate that there is a significant correlation between math anxiety and poor performance in math courses, but no such correlation is observed regarding performance in physics courses. In fact, Alvaro (1978) documented the presence of science anxiety in nonmath anxious students. Mallow (1986) listed numerous differences in math vs. science which could cause one anxiety but not the other, including: different field-dependences of the types of questions posed in science vs. mathematics (Gauld, 1979), the role of experimentation in science, and the students' sense of relevance of the two fields. Although there may be a component of math preparation in science anxiety, it is unlikely to play a large role. Biology, for example, has relatively little mathematics when compared with physics, yet students in the Loyola Science Anxiety Clinic expressed as much anxiety about biology as about physics. 


\section{Interventions for Teachers}

The American Association of Physics Teachers (AAPT) workshop for teachers, Developing Student Confidence in Physics (Fuller et al., 1985) has been offered periodically at AAPT national meetings. It features a personal self-inventory: a questionnaire describing various classroom scenarios and asking teachers to select their most likely responses. Responses are graded on a scale from "content" to "relationship," with the goal of balancing the two. The workshop then guides the teachers through a series of modules focusing on four aspects of teaching:

(1) the classroom learning environment,

(2) information transfer between teacher and student,

(3) teacher-student interactions, and

(4) teachers' evaluations of student performance.

Learning environment includes body language, tone of voice, word selection, and classroom organization by the teacher. Information transfer deals with all aspects of content, from course ground rules to teaching techniques, and how these can affect student confidence. Teacher-student interaction focuses primarily on the technique known as "active listening," helping teachers modify their listening styles so that they hear the student's whole agenda, not simply the superficial one presented. (Even such subtle but critical items as placement of chairs in the teacher's office are covered in this module.) Finally, evaluation of student performance deals not only with fair and effective grading, but with the nature of comments on papers and tests, and how these can diminish or enhance student confidence. An additional module deals specifically with issues of females and under-represented minorities in the science classroom. Workshop "graduates" are then expected to bring these techniques not only to their own classrooms, but to their colleagues as well. The workshop materials have also been used for binational comparison studies of teachers' reported styles in the US and Denmark (Mallow, 1995). We estimate that several hundred teachers in at least two countries have benefited from training in science anxiety reduction.

Finally, there is considerable work being done on modifying the "culture" of physics, especially in the college classroom. A summary of these efforts may be found in Whitten et al. (2003). Although these efforts are not described as explicit anxiety reducers, they outline numerous activities which fit the anxiety intervention model. They especially address the aspects of the traditional culture of physics which have been shown to alienate female students (Seymour and Hewitt 1997, 2000).

A comprehensive summary of gender issues in physics and more generally in science can be found online in Mallow and Hake (2002).

\section{APPENDIX B}

\section{Science Anxiety Questionnaire}

Date: Name:

The items in the questionnaire refer to things and experiences that may cause fear or apprehension. For each item, place a check mark on the line under the column that describes how much YOU ARE FRIGHTENED BY IT NOWADAYS.

Not at all A little A fair amount Much Very much

1. Learning how to convert Celsius to Fahrenheit degrees as you travel in Canada.

2. In a Philosophy discussion group, reading a chapter on the Categorical Imperative and being asked to answer questions.

3. Asking a question in a science class.

4. Converting kilometers to miles.

5. Studying for a midterm exam in Chemistry, Physics, or Biology.

6. Planning a well balanced diet.

7. Converting American dollars to English pounds as you travel in the British Isles.

8. Cooling down a hot tub of water to an appropriate temperature for a bath.

9. Planning the electrical circuit or pathway for a simple "light bulb" experiment.

10. Replacing a bulb on a movie projector.

11. Focusing the lens on your camera.

12. Changing the eyepiece on a microscope.

13. Using a thermometer in order to record the boiling point of a heating solution.

14. You want to vote on an upcoming referendum on student activities fees, and you are reading about it so that you might make an informed choice.

15. Having a fellow student watch you perform an experiment in the lab.

16. Visiting the Museum of Science and Industry and being asked to explain atomic energy to a 12-year old. 
17. Studying for a final exam in English, History, or Philosophy.

18. Mixing the proper amount of baking soda and water to put on a bee sting.

19. Igniting a Coleman stove in preparation for cooking outdoors.

20. Tuning your guitar to a piano or some other musical instrument.

21. Filling your bicycle tires with the right amount of air.

22. Memorizing a chart of historical dates.

23. In a Physics discussion group, reading a chapter on Quantum Systems and being asked to answer some questions.

24. Having a fellow student listen to you read in a foreign language.

25. Reading signs on buildings in a foreign country.

26. Memorizing the names of elements in the periodic table.

27. Having your music teacher listen to you as you play an instrument.

28. Reading the Theater page of Time magazine and having one of your friends ask your opinion on what you have read.

29. Adding minute quantities of acid to a base solution in order to neutralize it.

30. Precisely inflating a balloon to be used as apparatus in a Physics experiment.

31. Lighting a Bunsen burner in the preparation of an experiment.

32. A vote is coming up on the issue of nuclear power plants, and you are reading background material in order to decide how to vote.

33. Using a tuning fork in an acoustical experiment.

34. Mixing boiling water and ice to get water at $70^{\circ} \mathrm{F}$.

35. Studying for a midterm in an History course.

36. Having your professor watch you perform an experiment in the lab.

37. Having a teaching assistant watch you perform an experiment in the lab.

38. Focusing a microscope.

39. Using a meat thermometer for the first time, and checking the temperature periodically till the meat reaches the desired "doneness."

40. Having a teaching assistant watch you draw in Art class.
41. Reading the Science page of Time magazine and having one of your friends ask your opinion on what you have read.

42. Studying for a final exam in Chemistry, Physics, or Biology.

43. Being asked to explain the artistic quality of pop art to a 7th grader on a visit to the Art Museum.

44. Asking a question in an English Literature class.

\section{REFERENCES}

AAUW (1992). How Schools Shortchange Girls, American Association of University Women, Wellesley College Center for Research on Women, Wellesley, MA and AAUW Educational Foundation, Washington, DC.

Alpert, R., and Haber, R. N. (1960). Anxiety in academic achievement situations. Journal of Abnormal Psychology 61: 207215

Alvaro, R. (1978). The Effectiveness of a Science-Therapy Program on Science-Anxious Undergraduates, $\mathrm{PhD}$ dissertation, Loyola University Chicago.

Barnes, G. (1977). Scores on a Piaget-type questionnaire vs. semester grades for lower division college physics students. American Journal of Physics 45: 841-847.

Barnes, G., and Barnes, G. B. (1978). Students' scores on Piagettype questionnaires before and after taking one semester of college physics. American Journal of Physics 46: 807-809.

Beyer, K. (1991). Gender, science anxiety and learning style. Contributions to the Sixth GASAT ${ }^{3}$ (Gender and Science and Technology) Conference.

Beyer, K. (1992). Det er ikke tænkning det hele (Thinking isn't everything.). In Paulsen, A. Chr., and Nielsen, H. (Eds.), Om Undervisning i Fysik-den Konstruktivistiske Idé (On Physics Education: the Constructivist Idea. In Danish), Gyldendal, Copenhagen, pp. 118-158.

Beyer, K., Blegaa, S. and Vedelsby, M. (1985). Sex-roles and physics education. Contributions to the Third GASAT Conference.

Beyer, K., Blegaa, S., Olsen, B., Reich, J., and Vedelsby M. (1988). Piger og Fysik (Females and Physics. In Danish), IMFUFA Texts, Roskilde University Center, Roskilde, DK.

Beyer, K., and Reich, J. (1987). Why are many girls inhibited from learning scientific concepts in physics? Contributions to the Fourth GASAT Conference.

Beyer, K., and Vedelsby, M. (1983). Girls and physics-a Danish project. Contributions to the Second GASAT Conference.

Brownlow, S., Jacobi, T., and Rogers, M. (2000). Science anxiety as a function of gender and experience. Sex Roles: A Journal of Research 42: 119-131.

Brownlow, S., Smith, T. J., and Ellis, B. R. (2002). How interest in science negatively influences perception of women. Journal of Science Education and Technology 11: 135-144.

Brush, S. G. (1991). Women in science and engineering. American Scientist 79: 404-419.

Chiarelott, L., and Czerniak, C. (1985). Science anxiety among elementary school students: an equity issue. Journal Education Equity and Leadership 5: 291-308.

Chiarelott, L., and Czerniak, C. (1987). Science anxiety: Implications for science curriculum and teaching. The Clearing House 60: 202-205.

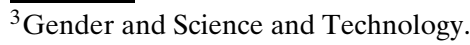


Claussen, C. (2004). Danish Ministry of Education, private communication.

Cohen, H. D., Hillman, D. F., and Agne, R. M. (1978). Cognitive level and college physics achievement. American Journal of Physics 46: 1026-1029.

Curtin, J., Blake, G., Cassagnau, C. (1997). 1995-1996 Academic Workforce Report, American Institute of Physics, College Park, MD.

Ellis, A. (1962). Reason and Emotion in Psychotherapy, Lyle Stuart, New York.

Fuller, R., Agruso, S., Mallow, J., Nichols, D., Sapp, R., Strassenburg, A. and Allen, G. (1985). Developing Student Confidence in Physics, American Association of Physics Teachers, College Park, MD.

Gauld, C. F. (1979). Physics teaching and cognitive functioninga neo-Piagetian perspective. The Physics Teacher 17: 513518.

Genshaft, J. L. (1982). The use of cognitive behavior therapy for reducing math anxiety. School Psychology Review 11: 3234.

Hake, R. (1998). Interactive engagement vs. traditional methods: A six-thousand student survey of mechanics test data for introductory physics courses. American Journal of Physics 66: 64-74.

Hall, D. W., Davis, N. B., Bolen. L. M., and Chia, R. (1999). Gender and racial differences in mathematical performance. Journal of Social Psychology 139: 677689.

Harrington, J., Davis, J., and Harrington, S. A. (1992). The use of PPST math scores to improve math skills for teacher education students. Education 112: 523-528.

Hermes, J. (1985). The Comparative Effectiveness of a Science Anxiety Group and a Stress Management Program in the Treatment of Science-Anxious College Students, PhD dissertation, Loyola University Chicago.

Ho, H. Z., Senturk, D., Lam, S. G., Zimmer, J. M., Hong, S., Okamoto, Y., Chiu, S., Nakazawa, Y., and Wang, C. (2000). The affective and cognitive dimensions of math anxiety: A cross-national study. Journal for Research in Mathematics Education 31: 362-379.

Ivie, R. (2004). Women in physics and astronomy. AAPT Announcer 33: 132

Jacobson, E. (1938). Progressive Relaxation, University of Chicago Press, Chicago.

Johnson, S., and Murphy, P. (1984). The underachievement of girls in physics: towards explanations. European Journal of Science Education 6: 401-411.

Jones, M. G., and Wheatley, J. (1988). Factors influencing the entry of women into science and related fields. Science Education 72: $127-142$.

Jones, M. G., and Wheatley, J. (1990). Gender differences in teacher-student interactions in science classrooms. Journal Research for Science Teaching 27: 861-874.

Kelly, A., (Ed.), (1981). The Missing Half: Girls and Science Education, Manchester University Press, Manchester.

Mallow, J. V. (1986). Science Anxiety: Fear of Science and How to Overcome It (revised edition), $\mathrm{H} \& \mathrm{H}$ Publications, Clearwater, FL.

Mallow, J. V. (1991). Reading science. Journal of Reading 34: 324 338.

Mallow, J. V. (1993). The science learning climate: Danish female and male students' descriptions. Contributions to the Seventh GASAT Conference.

Mallow, J. V. (1994). Gender-related science anxiety: A first binational study. Journal of Science Education and Technology 3: 227-238.
Mallow, J. V. (1995). Students' confidence and teachers' styles: A binational comparison. American Journal of Physics 63: 10071011.

Mallow, J. V. (1997). Science anxiety, nationality, and gender. Proceedings of the 16th Nordic Congress of Physics, Chemistry, and Mathematics Teachers (LMFK), Linköping, Sweden, pp. 83-96.

Mallow, J. V. (1998). Student attitudes and enrolments in physics, with emphasis on gender, nationality, and science anxiety. In Jensen, J. H., Niss, M., and Wedege, T. (Eds.) Justification and Enrolment Problems in Education Involving Mathematics or Physics, Roskilde University Press, Roskilde, DK, pp. 237258.

Mallow, J. V., and Greenburg, S. L. (1982). Science anxiety: causes and remedies. Journal of College Science Teaching 11: 356358.

Mallow, J. V., and Hake, R. R. (2002). Gender Issues in Physics/Science Education (GIPSE) - Some Annotated References. From http://www.physics.indiana.edu/ hake/GIPSE4b.pdf

Neuschatz, M., and Alpert. L. (1996). Overcoming Inertia: High School Physics in the 1990s (R-397), American Institute of Physics, College Park, MD.

NSF (1996). Women, Minorities, and Persons with Disabilities in Science and Engineering: 1996 (NSF 96-311), National Science Foundation, Washington, DC.

Piaget, J. (1967). The Psychology of Intelligence, Routledge and Paul, London, p. 148.

Renner, J. W., Stafford, D. G., Lawson, A. E., McKinnon, J. W. Friot, F. E., and Kellog, D. H. (1976). Research, Teaching, and Learning with the Piaget Model, University of Oklahoma Press, Norman, OK.

Richardon, R. C., and Suinn, R. M. (1972). The mathematics anxiety rating scale: Psychometric data. Journal Counselling for Psychology 19: 551-554.

Schneider, W.J., and Nevid, J.S. (1993). Overcoming math anxiety-a comparison of stress inoculation training and systematic-desensitization. Journal of College Student Development 34: 283-288, and references therein.

Seymour, E., and Hewitt, N. (1997, 2000). Talking About Leaving: Why Undergraduates leave the Sciences, Westview Press, Boulder, CO. Hardcover (1997), Paperback (2000).

Segal, S. (1987). Is female math anxiety real? Science 237: 350.

Spielberger, C. D., Gorsuch, R. L., and Lushene, R. E. (1970) STAI Manual for the State-Trait Anxiety Inventory, Consulting Psychologist Press, CA.

Tobias, S. (1978). Overcoming Math Anxiety, Norton, New York, Succeed with Math, The College Board, New York.

Tobias, S. (1985). Managing math anxiety: A new look at an old problem. Children Today. September-October: 7-9; Physics Today, June, p. 60

Tobias, S., Urry, M., and Venkatesan, A. (2002). Physics: for women, the last frontier. Science 296: 1201.

Udo, M. K., Ramsey, G. P., Reynolds-Alpert, S., and Mallow, J. V. (2001). Does physics teaching affect gender-based science anxiety? Journal of Science Education and Technology 10: 237-247.

Vedelsby, M. (1991). Myter og Realiteter: Kvinder i naturvidenskabelige og teknologiske uddannelser (Myths and Realities: Women in Scientific and Technological Education. In Danish), Forskningspolitisk Råd, Copenhagen.

Whitten, B. L., Foster, S. R., and Duncombe, M. I. (2003). What works for women in undergraduate physics? Physics Today 56: 46-51.

Yater, J. (1986). Math anxiety and physics. Physics Today 39: 15 and replies therein. 